Healthcare Profile:

Networks Share, Access and Store Digital Medical Images: The Thames Valley Initiative
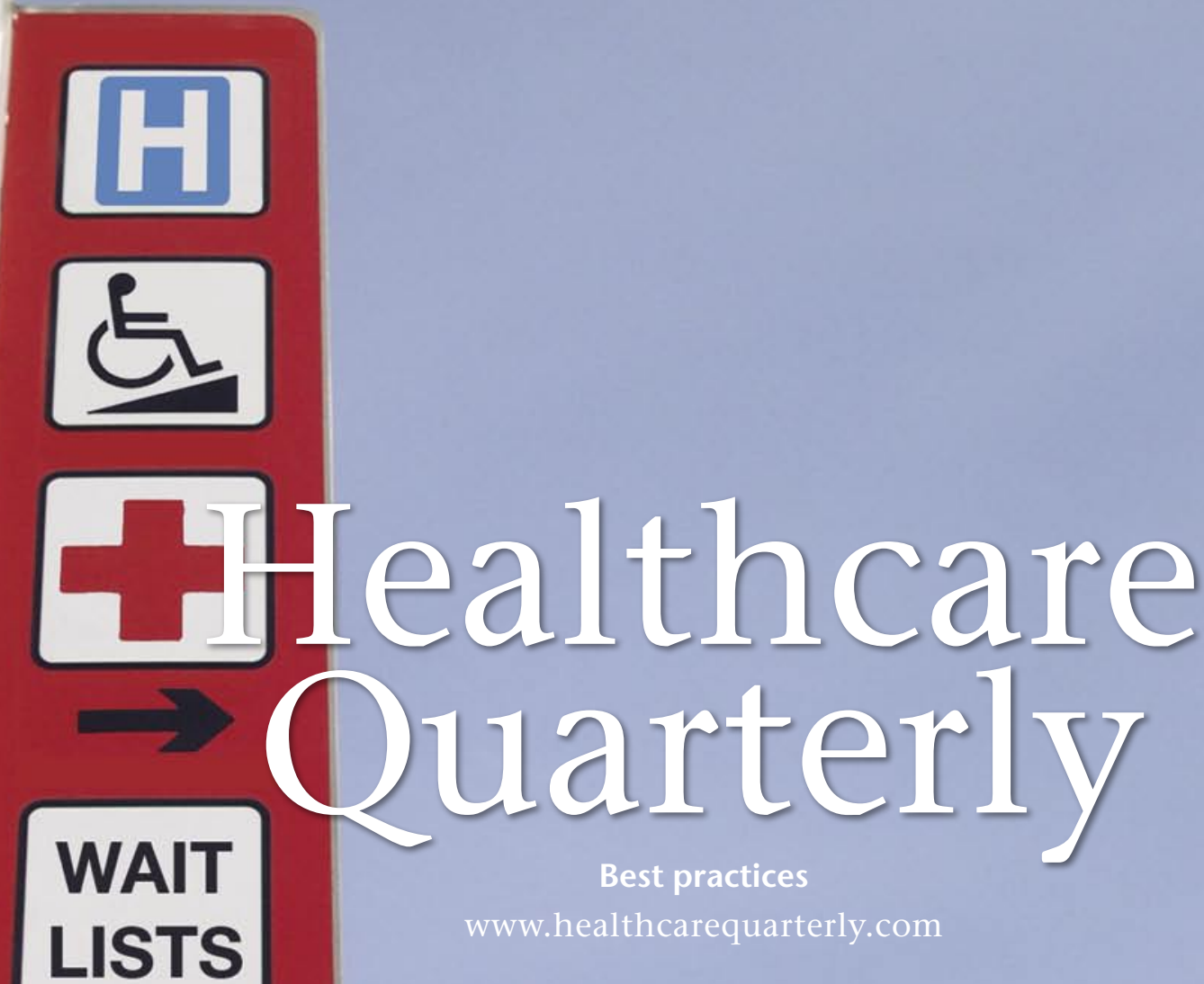

Experiences of Regionalization:

Assessing Multiple Stakeholder Perspectives across Time

Ann Casebeer, Trish Reay, Karen Golden-Biddle, Amy Pablo, Elden Wiebe and Bob Hinings

Towards Faster Treatment: Reducing Attendance and Waits at Emergency Departments

Longwoods Review

A Collaborative Approach to Building Capacity in Health Informatics

Francis Lau ElectronicHealthcare

Perspective • Ideas at Work • Online Case Study • Book Review • Futurethink 


\title{
Networks Share, Access and Store Digital Medical Images: The Thames Valley Initiative
}

\author{
David Mosher
}

Offices across the country may not be paperless. And they probably don't need to be. But with the establishment of a Digital Imaging Network, some of Southwestern Ontario's hospitals are becoming 'filmless', and the delivery of healthcare services is being transformed to improve the quality of patient care.

The Thames Valley Hospital Planning Partnership (TVHPP) consists of eight healthcare institutions in the region: Alexandra Hospital in Ingersoll; Four Counties Health Services in Newbury; London Health Sciences Centre; St. Joseph's Health Care in London; St. Thomas Elgin General Hospital; Strathroy Middlesex General Hospital; Tillsonburg District Memorial Hospital; and Woodstock General Hospital. The TVHPP has implemented a Digital Imaging Network solution that enables its healthcare providers quickly and securely to share, access and store digital medical images, such as X-rays, MRIs, ultrasounds and CT scans, across departments and medical facilities.

This network, based on information and communications technologies, facilitates knowledge-sharing and improves diagnoses, as the consultative process is significantly enhanced with authorized specialists in any of the member hospitals having immediate access to a patient's images. And it eliminates the expensive use of film.

The TVHPP's Digital Imaging Network also reduces the need for radiologists and patients to travel or be transferred from one institution to another, as can be the case particularly in rural communities. Patients can receive care closer to home, as images can be accessed by specialists anywhere on the network. And so the speed and accuracy of treatment decisions are enhanced.

"We are improving patient care with our ability to access and exchange medical images and information. Patients don't have to wait for images to be developed and manually transferred," said Dr. Donald Taves, chief of radiology, St. Joseph's Health Care London and a professor at the University of Western Ontario.
"They are immediately available for review, even from a remote site," he added. "Now, a patient can leave the department after the images have been taken knowing that the specialist will be able to review and then discuss their case promptly. No lost or misplaced film is an added benefit."

Hospitals are mitigating the shortage of diagnostic imaging professionals in the province, and the requirements of smaller hospitals, which may not be able to afford their own radiology departments even if specialists are available to staff them, are now addressed.

Healthcare providers can have a full view of a patient's medical history, with images and reports accessible as part of his or her electronic health record, making it easier to treat patients efficiently, affordably and reliably. And patient management is enhanced through the tracking of order status and the greater availability of radiologists.

Film searches have been eliminated and procedure duplications greatly reduced, which increases productivity and saves time. Storage space requirements have been drastically reduced and, for example, London Health Sciences Centre has achieved $\$ 1.2$ million in film savings alone.

The TVHPP was formed to co-operatively explore the feasibility of integrating and sharing strategic healthcare services and priorities, including diagnostic imaging, clinical care, laboratory systems and capital planning.

Many hospitals in the region were seeking opportunities to form strategic alliances as some require access to the expertise and resources outside of their own settings to meet the needs of their patients. 
The TVHPP's Digital Imaging Network, one of the first IT shared services projects in Canada, emerged with the objectives of enhancing the efficiency of service delivery and eliminating duplicate practices across the member hospitals. The project is unique because, as a shared initiative, the hospitals have agreed to adopt and use common standards and infrastructure, rather than each developing its own system.

"We are transforming the delivery of patient services with this solution and through our collaborative efforts in the region," said Diane Beattie, integrated vice president and chief information officer, London Health Sciences Centre and St. Joseph's Health Care London.

The TVHPP project is funded by Canada Health Infoway, an independent, not-for-profit corporation that supports the development of electronic health information systems across the country, and the Ontario Ministry of Health and Long-Term Care.

The imperative for information and communications technology solutions in the healthcare sector is clear. They must be able to support the use, access and distribution of medical and administrative applications, records and data among all stakeholders in the healthcare ecosystem.

They must also enable healthcare organizations to drive operational efficiencies, improve productivity and reduce costs, as well as simplify their IT environments and integrate new technologies.

Healthcare technology solutions need to meet the challenge of the ever-increasing volumes of healthcare information and provide the flexibility to manage this data across tiers of storage, along with continuous, proactive checking to ensure data integrity. They can also assist healthcare organizations to comply with regulatory and privacy requirements for the storage, transmission and protection of patient data.

By aligning their IT infrastructure - which comprises all of their computing hardware, software and services - with their business processes, organizations will be able to more effectively adapt to clinical and regulatory changes, and ultimately improve patient care and safety.

The TVHPP's Digital Imaging Network project encompasses a number of innovative technologies from leading vendors, such as Hewlett-Packard's (HP) Medical Archiving Solution, which provides a shared IT infrastructure for the long-term storage of medical images.
Part of HP's information life cycle management portfolio, the HP Medical Archiving Solution is designed for radiology practices within hospitals, clinics and diagnostic imaging centres. The Medical Archiving Solution enables healthcare providers to access vital information securely and simultaneously in order to collaborate, wherever they are located.

"HP has considerable experience and expertise in the healthcare sector, so we were very confident that they could support our mission to meet the needs of our communities with a patient-centred philosophy and innovative models of patient care," said Beattie.

HP teamed on the project with GE Healthcare, a major provider of transformational medical technologies, and Cerner Corp., a leading supplier of healthcare information technology. GE Healthcare is providing the picture archiving and communication system (PACS) and Cerner is providing its Cerner Millennium ${ }^{\circledR}$ platform for electronic patient records and radiology.

The Medical Archiving Solution is based on open standards for interoperability, and individual hospitals, imaging clinics or large hospital systems can share their infrastructure to house image types used in different PACS. Users can integrate text-based information from health information systems, such as patient records and insurance data, into the solution and migrate images from various PACS to one centralized, consolidated, long-term storage solution.

To build on the success of the TVHPP project, planning is underway to expand the shared digital imaging network to other Southwestern Ontario area hospitals. The work of TVHPP in transforming healthcare services is being watched and evaluated by healthcare institutions around the world.

It is an historic step forward in using information and communications technology to enhance patient care while streamlining processes. The project is leading the way in creating the shared model that will accelerate the flow of patient information, reduce operating costs and heighten the responsiveness of healthcare services.

\section{About the Author}

David Mosher is the Healthcare Business Manager at HewlettPackard (Canada) Co. in Mississauga, Ontario. He can be contacted at: david.mosher@hp.com 